\title{
Should We Measure Vitamin D Level?
}

\author{
Jae Hwa Cho, M.D.
}

Division of Pulmonology and Critical Care Medicine, Department of Internal Medicine, Inha University College of Medicine, Incheon, Korea

Vitamin D deficiency (serum 25-hydroxyvitamin D > 10 ng per milliliter) increases the risk of bone fracture and muscle weakness. Vitamin D insufficiency is defined as a serum level of 25 -hydroxyvitamin $\mathrm{D}\left(25[\mathrm{OH}] \mathrm{D}_{3}\right)$ of 10 to $30 \mathrm{ng}$ per milliliter without obvious clinical disease.[1] During the past decade, the effects of vitamin D insufficiency have been studied in cancer, cardiovascular disease, diabetes mellitus, endocrine disorders and immune dysfunction.[1]

In the Korea National Health and Nutrition Examination Survey, the prevalence of serum $25[\mathrm{OH}] \mathrm{D}_{3}<20 \mathrm{ng}$ per milliliter was $47.3 \%$ in males and $64.5 \%$ in females.[2] In a pilot study, vitamin D insufficiency in patients admitted to intensive care units in the Daegu metropolitan area comprised 87.8\%.[3,4] Short-term and mid-term mortality rates were not associated with vitamin D levels, however.[3.4] Vitamin D plays key roles in immune regulation, infection susceptibility and progression of acute respiratory distress syndrome.[5,6] Many studies have suggested that vitamin D replacement therapy reduces mortality in various diseases. In a meta-analysis, vitamin D supplementation seemed to reduce mortality rates in elderly patients.[7] However, the methods of administering vitamin D varied and we did not find appropriate way of vitamin D therapy.

Clinical outcomes according to vitamin D level have not been determined. Beyond basic research, clinical studies using vitamin D are needed in critical and intensive care medicine. Prospective studies on vitamin D replacement in critically ill patients with vitamin D deficiency are ongoing.[8] Regular monitoring of serum $25[\mathrm{OH}] \mathrm{D}_{3}$ should be considered in severely ill patients.

\author{
Jae Hwa Cho \\ Division of Pulmonology and Critical \\ Care Medicine, Department of Internal \\ Medicine, Inha University College of \\ Medicine, 27 Inhang-ro, Jung-gu, \\ Incheon 22332, Korea \\ Tel: $+82-32-890-3490$ \\ Fax: $+82-32-882-6578$ \\ E-mail: jaehwa.cho@inha.ac.kr \\ ORCID \\ Jae Hwa Cho \\ http://orcid.org/0000-0002-3432-3997 \\ *No potential conflict of interest relevant to this \\ article was reported.
}

\section{References}

1) Rosen CJ: Clinical practice. Vitamin D insufficiency. N Engl J Med 2011; 364: 248-54. 
2) Choi HS, Oh HJ, Choi H, Choi WH, Kim JG, Kim KM, et al: Vitamin D insufficiency in Korea-a greater threat to younger generation: the Korea National Health and Nutrition Examination Survey (KNHANES) 2008. J Clin Endocrinol Metab 2011; 96: 643-51.

3) Kim HJ, Sohn MS, Choi EY. Prevalence and related factors of vitamin D deficiency in critically Ill patients. Korean J Crit Care Med 2016; 31: 300-7.

4) Ala-Kokko TI, Mutt SJ, Nisula S, Koskenkari J, Liisanantti J, Ohtonen P, et al: Vitamin D deficiency at admission is not associated with 90-day mortality in patients with severe sepsis or septic shock: observational FINNAKI cohort study. Ann Med 2016; 48: $67-75$

5) Upala S, Sanguankeo A, Permpalung N: Significant association between vitamin D deficiency and sepsis: a systematic review and meta-analysis. BMC Anesthesiol 2015; 15: 84 .

6) Dancer RC, Parekh D, Lax S, D'Souza V, Zheng S, Bassford CR, et al: Vitamin D deficiency contributes directly to the acute respiratory distress syndrome (ARDS). Thorax 2015; 70: 617-24.

7) Bjelakovic G, Gluud LL, Nikolova D, Whitfield K, Krstic G, Wetterslev J, et al: Vitamin D supplementation for prevention of mortality in adults. Cochrane Database Syst Rev 2014; (6): CD007470.

8) Han JE, Jones JL, Tangpricha V, Brown MA, Brown LA, Hao L, et al: High dose vitamin D administration in ventilated intensive care unit patients: a pilot double blind randomized controlled trial. J Clin Transl Endocrinol 2016; 4: 59-65. 